\title{
Erratum to: Effect of strontium-containing hydroxyapatite bone cement on bone remodeling following hip replacement
}

\author{
Guo X. Ni • Jian H. Lin • Peter K. Y. Chiu • \\ Zhao Y. Li · William W. Lu
}

Published online: 13 March 2010

(C) Springer Science+Business Media, LLC 2010

Erratum to: J Mater Sci: Mater Med (2010)

\section{1:377-384}

DOI 10.1007/s10856-009-3866-2

The authors have submitted revised affiliations for the article listed above, published in Journal of Materials Science: Materials in Medicine 2010; 21:377-384. The correct affiliations are given below.

The online version of the original article can be found under doi:10.1007/s10856-009-3866-2.

G. X. Ni ( $($ )

Department of Orthopaedics and Traumatology, Nanfang

Hospital, Southern Medical University, Guangzhou 510515,

China

e-mail: fgxni@graduate.hku.hk

J. H. Lin

Department of Orthopaedic Surgery, No. 1 Affiliated Hospital,

Fujian Medical University, Fuzhou, China

P. K. Y. Chiu · Z. Y. Li · W. W. Lu (ه)

Department of Orthopaedics and Traumatology, The University

of Hong Kong, Hong Kong, Hong Kong

e-mail:wwlu@hkusua.hku.hk 